\title{
Superplastic forming of AZ31 magnesium alloy with controlled microstructure
}

\author{
Superplastisches Umformen der Magnesiumlegierung MgAl3Zn1 (AZ31) \\ mit gesteuerter Mikrostruktur
}

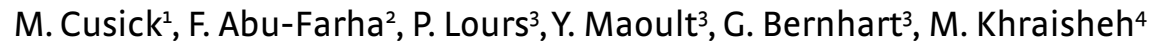

\begin{abstract}
A recent study on post-superplastic forming properties has shown that heating time prior to testing has a major effect on the post-forming properties of superplastically-formed AZ31 Magnesium alloy sheets. To this point, there has been very little examination into the effects of preheating or annealing on superplastic forming. In this work, these effects are examined using AZ31 Mg alloy samples. Both tensile specimens and bulge sheets were superplasticallystretched after undergoing different annealing routes. Multiple annealing temperatures and times were examined to produce specimens with grain sizes ranging from 8 to $15 \mu \mathrm{m}$, for comparison with traditional SPF results. The results show that annealing treatments can be suitable for the improvement of thinning and forming time of superplastically-formed Magnesium alloys through the control of the microstructure.
\end{abstract}

Keywords: Annealing / Magnesium / Superplastic Forming / Selective Control of Microstructure

Schlüsselwörter: Wärmebehandlung / Magnesium / Superplastisches Verformen / selektive Steuerung der Mikrostruktur

\section{Introduction}

As the search for means of reducing our carbon footprint continues, the demand for lightweight alloys grows substantially. The conventional formability of lightweight alloys such as Aluminum, Titanium, and Magnesium remains limited due to their poor low temperature ductility. This deficiency of formability joined by higher demand has promoted the detailed investigation and use of advanced forming techniques. Superplastic forming is one of these techniques that is gradually gaining momentum as research furthers the understanding and forming properties. Superplastic forming targets extreme ductility at elevated temperatures permitting large strains to be incurred in a sheet material. Of course, after initial research studies, all probable forming techniques are studied for optimum formability. Due to the largest ductility being associated with lower strain rates, initial mod-

${ }^{1}$ Center for Manufacturing and Mechanical Engineering Dept., Univesity of Kentucky, Lexington, KY, USA

${ }^{2}$ School of Engineerig, Penn State Erie, 5101 Jordan Road, 246 REDC, Erie, PA 16563, USA

${ }^{3}$ Université de Toulouse, Institut Clément Ader, Mines d’Albi, Campux Jarlard, Albi, France

${ }^{4}$ Masdar Institute of Science and Technology, Masdar City, Abu Dhabi, UAE

Corresponding author: M. Khraisheh, Masdar Institute of Science and Technology, Masdar City, Abu Dhabi, UAE

E-mail: mkhraisheh@masdar.ac.ae eling investigations focused on variable strain rate techniques [13]. These initial studies were strictly based on strain rates, and the initial variable strain rate models were determined by trial and error from experiments. Currently, a new multi-scale stability criterion has been shown to exhibit a better optimization procedure through the incorporation of micro-scale parameters, cavitation and grain growth, and geometrical features [4]. With the incorporation of the criterion into a simplified uniaxial model, investigators were able to determine the optimum variable strain rate path at a forming temperature of $400^{\circ} \mathrm{C}$ for AZ31 magnesium alloy $[5,6]$.

With these types of material models providing such optimized material deformation paths, there is a need to evaluate the effects of pre and post forming factors. Post superplastic deformation material properties have begun to be investigated, leading to the understanding that the largest post forming effects are due to heating [7]. Since heating of the specimen primarily affects its microstructure, there is a relevant possibility that the evaluation of microstructural effects in SPF can be incorporated into the process. Such ideas include selective grain size modification to offset thinning as well as increasing forming times. Recently, work on determining the validity of microstructural engineering for means of thinning reduction have been studied, providing an introduction to such an idea $[8,9]$. Initial modeling results for microstructurally-engineered SPF samples have shown a great deal of influence on thinning in bulge forming [10]. But to this point, such investigations have focused on the results of microstructure engineering for bulge forming. For full understanding, material properties must be 
investigated to allow simulation results to assist the work, if useful results are ever to be obtained.

In this work, the abovementioned selective grain growth work for AZ31 Mg alloy has been started with promising results, leading to the need for a detailed study to determine its full potential. Not only for a means of sustainably controlling SPF thinning, but also for the possibility of increased forming rates, which are highly desired in the manufacturing sector. A static grain growth map for AZ31 Mg alloy is presented for the aid of bulge forming annealing selection. Tensile specimens for multiple temperatures and annealing times are examined, in order to determine the effects on the flow and ultimate stresses, in the AZ31 Mg alloy. Finally, an initial investigation of the effect of selective heating on bulge forming is also presented.

\section{Experiments}

\subsection{D Static grain growth maps}

The most important factor in SPF microstructural engineering is the ability to repeatedly predict and generate desired microstructures. To provide such ability, a 3-D static grain growth map was generated from a series of annealing experiments. Mg AZ31 has a melting temperature of $\sim 630^{\circ} \mathrm{C}$, and previous safety tests showed that temperatures above $500^{\circ} \mathrm{C}$ cause severe oxidation. So, annealing temperatures were chosen to be $225,300,375$ and $450^{\circ} \mathrm{C}$. For each temperature, annealing times between 15 minutes and 24 hours were used, with an emphasis on the $0-2 \mathrm{~h}$ range. These annealing schemes were applied to samples taken from two sheets; one with a thickness of $3.22 \mathrm{~mm}$, and another with a thickness of $1.07 \mathrm{~mm}$. The thicker sheet is later used to prepare tensile testing specimens, while the thinner sheet is used to prepare bulge forming specimens. After annealing, microstructural examination was carried out on selected specimens according to the ASM standard procedures [11], and microstructure was analyzed by optical microscopy. Grain size for both the as-received and annealed specimens was determined using the mean linear intercept method. A magnification of $1000 \times$ was used for as-received specimens, while $625 \mathrm{x}$ was the magnification used to generate the static grain growth curves. Grain growth results for each individual temperature were fit two dimensionally using a logarithmic curve; the logarithmic curves were then combined on a single plot to provide a 3-D static grain growth map for Mg AZ31.

\subsection{Uniaxial superplastic testing of fully-annealed specimens}

Pre-annealed AZ31Mg dog-bone specimens (prepared from the $3.22 \mathrm{~mm}$ sheet) were superplastically-tested in simple tension at $400^{\circ} \mathrm{C}$, using a 5582 INSTRON Load Frame and a 651 INSTRON environmental chamber. Pre-annealing was carried out at two temperatures; 300 and $450{ }^{\circ} \mathrm{C}$, for two annealing times; 30 and 60 minutes. The tensile specimens were stretched at constant strain rates of $1.0 \times 10^{-2}, 2.5 \times 10^{-3}, 5.0 \times 10^{-4}$ and $1.0 \times 10^{-4} \mathrm{~s}^{-1}$. In addition, strain rate jump tests between strain rates of $2.5 \times 10^{-3}$ $5.0 \times 10^{-3} \mathrm{~s}^{-1}$ and $2.0 \times 10^{-4}-5.0 \times 10^{-4} \mathrm{~s}^{-1}$ were performed, in order to generate strain rate sensitivity comparisons. Microstruc-

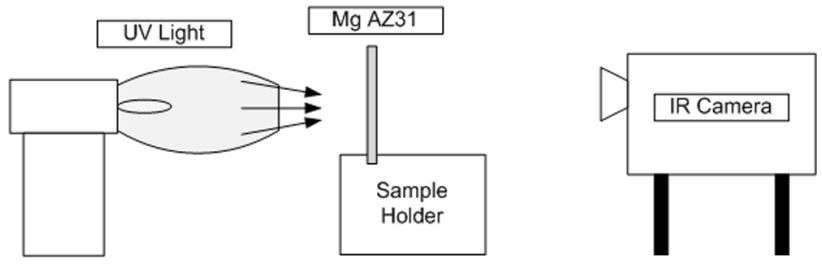

Figure 1. Selective annealing experimental setup.

tural analysis was performed the same way as mentioned in section 2.1, but with a magnification of $500 \times$.

\subsection{Superplastic bulge forming of selectively annealed sheets}

Selective annealing was performed using a Spot IR infrared heater (model 4085 from Research Inc.), controlled by a linear voltage regulator; the setup is shown in Figure 1. The Spot IR heater was used to selectively heat 5 sheet samples that were approximately $75 \mathrm{~mm} \times 75 \mathrm{~mm}$, and with a thickness of $1.07 \mathrm{~mm}$. The samples were held vertically in front of the light source, which had a polished shield to focus the light into a $\sim 37 \mathrm{~mm}$ circle. The analysis for temperature gradients was provided by the collection of infrared data gathered during the experiment. The IR camera was located behind the specimens, and the data was saved using a DAQ loaded with IR software ADDEILE. The specimens were coated with a black charcoal colored paint to permit accurate temperature readings. Specimen 1 was used as a reference specimen to determine the desired heating temperature according to the temperature distribution across the specimen. For this work, all temperature references for the selectively heated bulge specimens refer to the maximum temperature located at the center of the specimen. Specimen 1 was heated for 15 minutes at a maximum temperature of $400^{\circ} \mathrm{C}$ and 15 minutes at a maximum temperature of $450^{\circ} \mathrm{C}$. Specimens 2 through 5 were heated for 25 minutes at a maximum temperature of $400^{\circ} \mathrm{C}$. After the selective annealing, specimen 3 was examined microstructurally for grain size variance. Specimens 1 and 2 were superplastically bulgeformed at $400^{\circ} \mathrm{C}$, using the bulge forming setup described by (Abu-Farha 2007) [12]. The bulge forming of specimens 1 and 2, as well as the as-received specimen, was carried out at a constant temperature of $400{ }^{\circ} \mathrm{C}$, with a pressure-time profile generated from the analytical solution by Mukherjee and Dutta [13].

\section{Results}

\subsection{D Static grain growth maps}

To fit the obtained grain growth data, the typical physical law for static grain growth, its form is provided in equation 1 , was first examined:

$D^{n}=D_{0}^{n}+k t$

For all temperatures, plots of $D^{n}$ versus $t$ were generated for all integer numbers of $n$ from 2 to 14. Linear fits were then carried out to determine the values of $n$ and $K$, knowing $t, D$, and $D_{0}$. After all the plots were finished, the $\mathrm{R}^{2}$ value for a linear fit was 


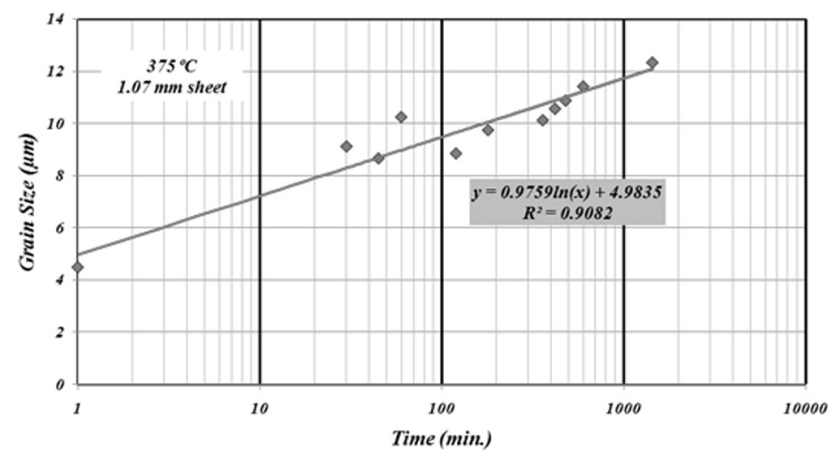

(a)

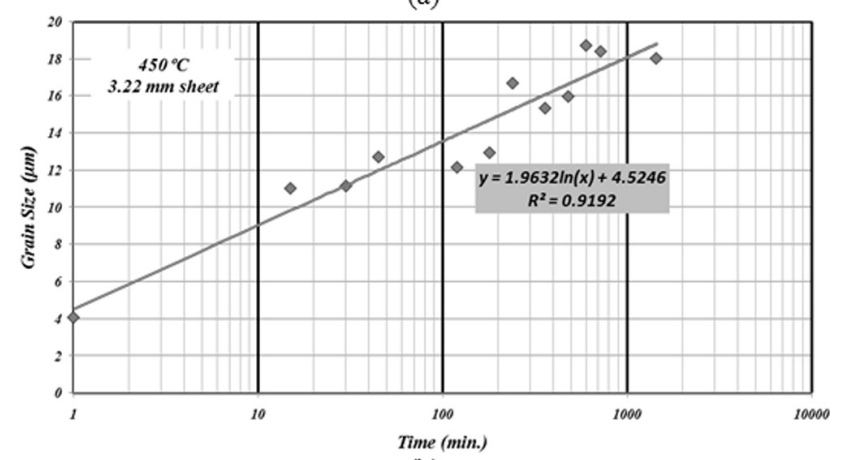

(b)

Figure 2. Static grain growth curve for the AZ31 magnesium alloy for 24 hours at (a) $375^{\circ} \mathrm{C}$ (b) $450^{\circ} \mathrm{C}$.

found to be a max of 0.6 for each temperature, but with a different $n$ value from temperature to another ( $n$ varied from 4 to 12 depending on the temperature). The results did not fit the description of the physical law of static grain growth, and thus an empirical fit using equation 2 was used instead.

$D=A \ln t+D_{0}$

Figure 2 shows the fit plots for two selected temperatures; $375^{\circ} \mathrm{C}$ for the $1.07 \mathrm{~mm}$ thick sheets and $450^{\circ} \mathrm{C}$ for the $3.22 \mathrm{~mm}$ thick sheets. The fit plots for all the four annealing temperatures were combined to create the 3-D static grain growth surfaces shown in Figure 3. As can be seen from the figures, the fits are marginal due to the large variation in grain size throughout the specimens; yet they show consistent logarithmic trends. The logarithmic trends were consistent from test to test, leading to the logarithmic contour plot used for estimating grain size for the selectively-annealed bulge forming sheet specimens.

\subsection{Uniaxial SP stretching of fully-annealed specimens}

As mentioned earlier, uniaxial stretching at superplastic conditions was carried out on pre-annealed specimens (all cut from the $3.22 \mathrm{~mm}$ thick sheet) for 4 annealing combinations; the results are presented in the true stress/strain plots in Figures 4. The darkest curve in each plot is the as-received results determined by (AbuFarha 2007) [12], and is used here as the basis of comparison. The stress/strain curves reveal slight increases in the flow and peak flow stresses of the annealed specimens. Ductility, on the other hand, decreased due to the larger microstructure present during SP stretching. The larger microstructure has a similar

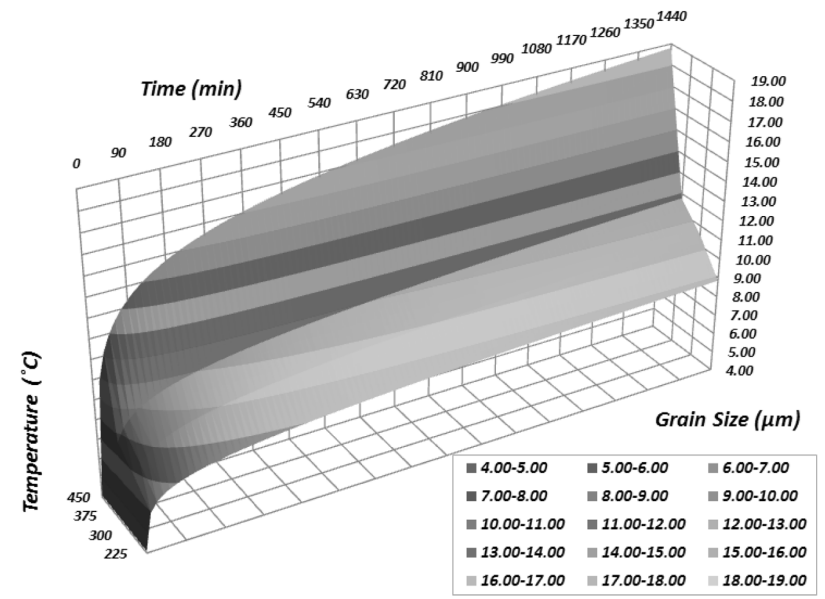

(a)

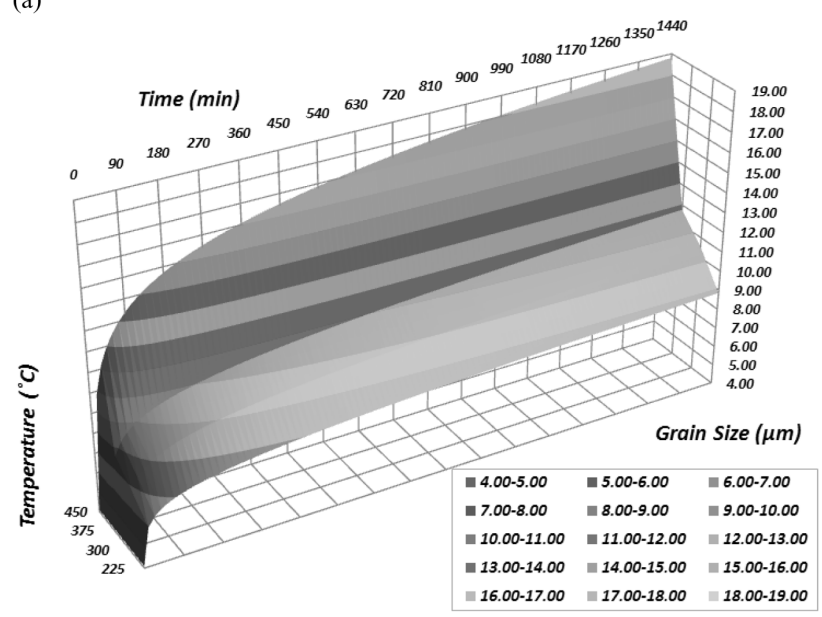

(b)

Figure 3. Static grain growth contour plots for the AZ31 magnesium alloy (a) $3.22 \mathrm{~mm}$ thick sheets (b) $1.07 \mathrm{~mm}$ thick sheets.

effect as rapid dynamic grain growth, which is very important due to the direct link to the deformation mechanism (grain boundary sliding).

Though ductility decreases for the annealed specimens, the increase in flow stress was the desired property for selective microstructure engineering, Figure 5. It is important to note that the small grain size variation in the tensile specimen results is due to the required preheating of the system prior to testing. Each specimen is placed in the furnace during the temperature ramp up, which sizably alters the microstructure of the material from its initial microstructure, which is much more inhomogeneous and strain hardened. The 3-D static grain growth map was not used for the tensile specimens due to the 45 minutes preheating time for superplastic stretching. To guarantee thermal equilibrium, the environmental chamber, and the tensile specimen within, were both heated from room temperature to $400^{\circ} \mathrm{C}$ for 45 minutes. Thereafter, superplastic stretching was imposed on the specimen. This double heating time is not categorized in the static grain growth work.

Strain rate jump tests were used to examine the effect of pre annealing on strain rate sensitivity, and the results are provided in Figures 6. As expected, the strain rate sensitivity decreases a 


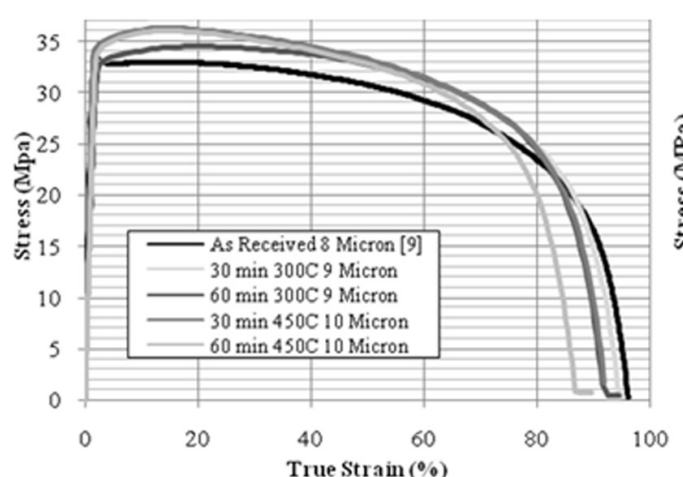

(a)

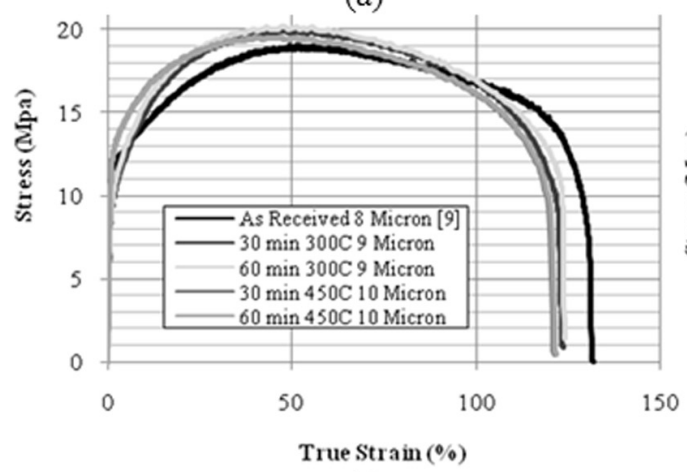

(c)

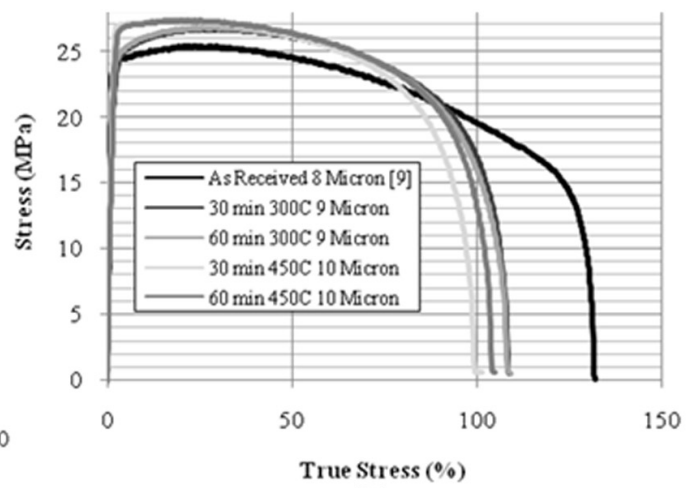

(b)

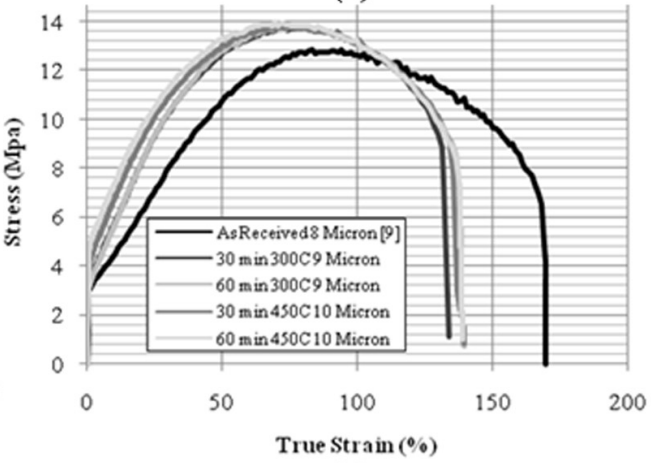

(d)

Figure 4. Effect of pre-annealing on superplastic tensile properties in the AZ31 magnesium alloy at $400^{\circ} \mathrm{C}$ and (a) $1 \times 10^{-2} \mathrm{~s}^{-1}$ (b) $2.5 \times 10^{-2} \mathrm{~s}^{-1}$ (c) $5 \times 10^{-4} \mathrm{~s}^{-1}$ (d) $1 \times 10^{-4} \mathrm{~s}^{-1}$.

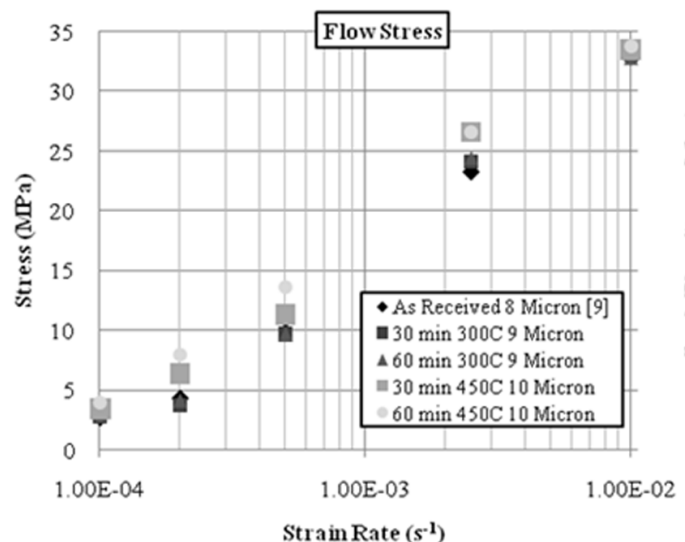

(a)

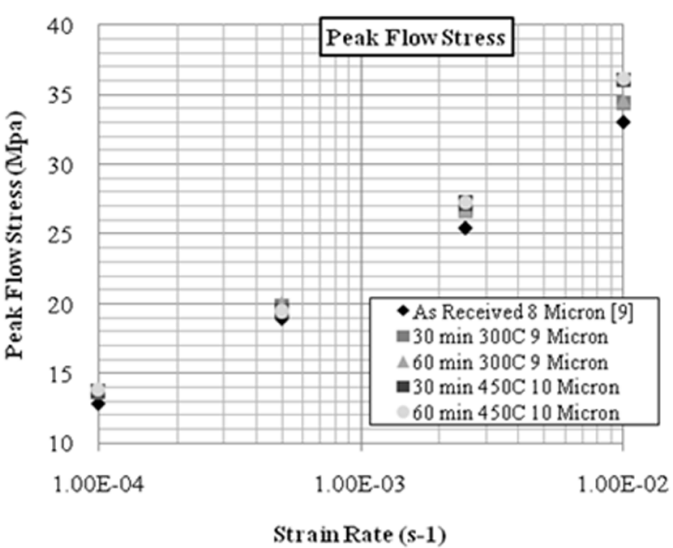

(b)

Figure 5. Effect of pre-annealing on the (a) flow stress (b) peak flow stress, in the AZ31 magnesium alloy at $400{ }^{\circ} \mathrm{C}$.

small amount due to annealing. Due to the increase in grain size and healing of the material's microstructure during annealing, the superplastic properties are shifted to lower strain rates.

\subsection{Superplastic bulge forming of selectively-annealed sheets}

Selective annealing was investigated in order to determine if engineered microstructure may have a large impact on the superplastic forming of magnesium alloys. Figure 7 shows the cap- tured temperature profiles from specimens 2 and 3. It is clear that the heating setup was consistent within a few degrees centigrade. Specimen 1 was the test specimen used to determine the required voltage for a maximum surface temperature of $400^{\circ} \mathrm{C}$ in test specimens 2 through 5 . Thus, specimen 1 was heated for a longer period of time and with heating durations at $350^{\circ} \mathrm{C}$, $400^{\circ} \mathrm{C}, 425^{\circ} \mathrm{C}$ and $450^{\circ} \mathrm{C}$. This provides the explanation for the substantial SPF forming difference from specimen 2.

Microstructural examination was successfully carried out on specimen 3, but specimens 4 and 5 were lost due to complica- 


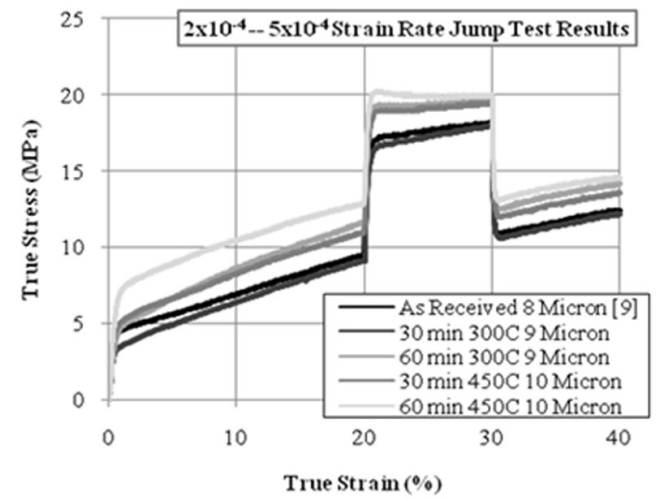

(a)

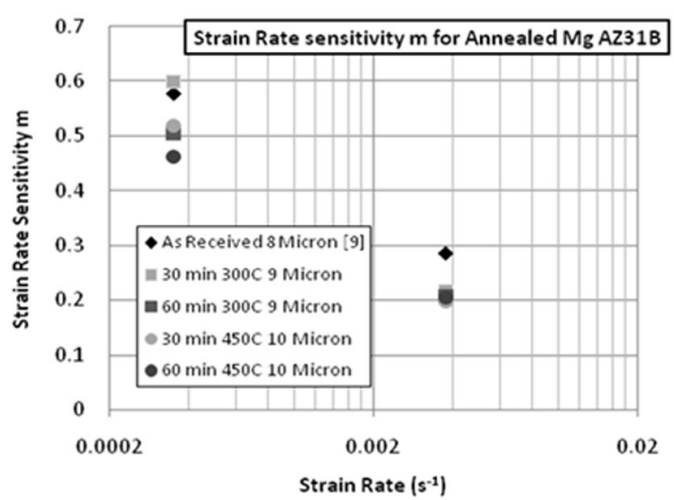

(b)

Figure 6. Effect of pre-annealing on the (a) strain rate jump tests (b) strain rate sensitivity of the AZ31 magnesium alloy at $400{ }^{\circ} \mathrm{C}$.

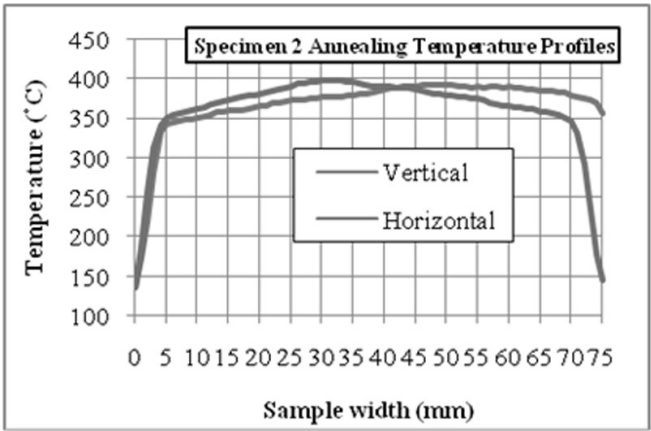

(a)

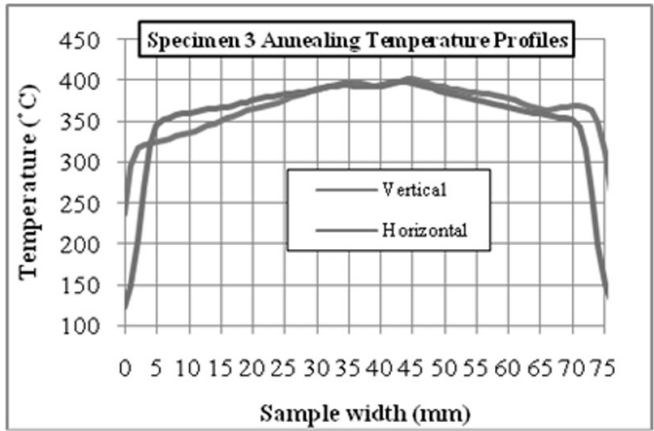

(b)

Figure 7. Temperature profile across the middle of the selectively-heated AZ31 Mg bulge-formed sample for 25 minutes (a) Specimen No. 2 (b) Specimen No. 3.

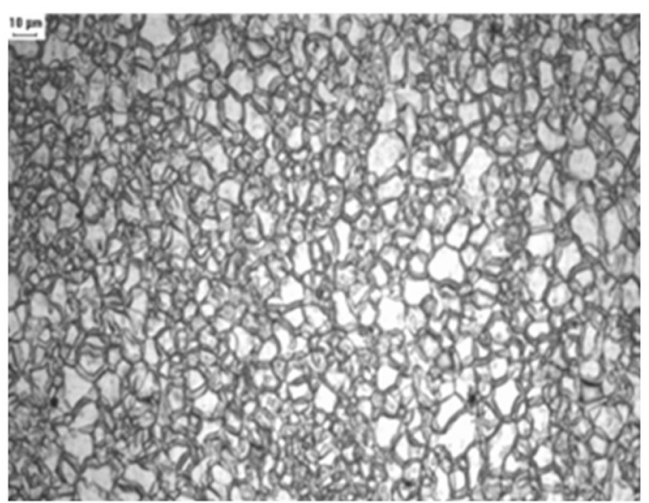

(a)

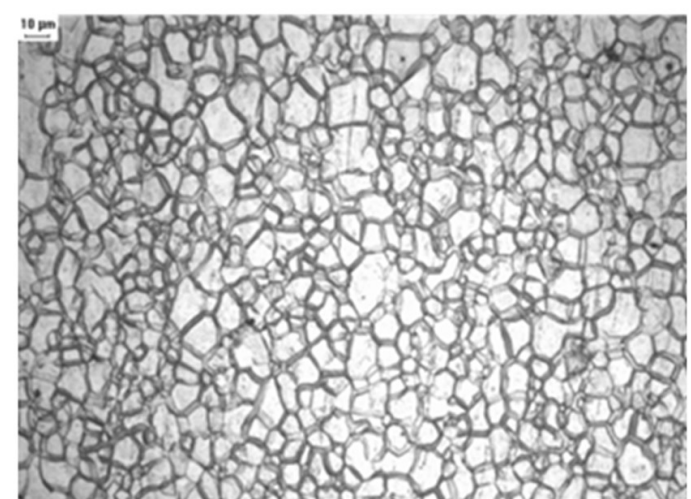

(b)

Figure 8. Microstructure of selectively-heated AZ31 Mg bulge-forming Specimen No. 3 at the (a) outer edge (b) center.

tions in trying to mount and polish after selective heating. Examples of the Microstructure of specimen 3 are provided in Figure 8, which shows the microstructure near the outside edge and the center of the specimen. These microstructure images clearly show the changes caused by annealing, when compared with the as-received. On the other hand, there is a clear grain size difference between the two parts of Figure 8, and even though the gradient is not as large as desired, it still demonstrates how a desired microstructure gradient can be achieved.
Going to the next phase of superplastic forming of the selectively-heated samples, monitoring the forming height of each sample provides an insight on the direct effects of annealing on SPF of the Mg AZ31 alloy, Figure 9. Specimen 1 was selectivelyheated for nearly 40 minutes, which is 15 minutes longer than the rest of specimens. Also, specimen 1 was heated to temperatures of $425^{\circ} \mathrm{C}$ and $450^{\circ} \mathrm{C}$ for nearly 10 minutes each, which would create a major difference in the microstructure by nearly 2 $\mu \mathrm{m}$, based on the static grain growth results, Figure 3. This dif- 


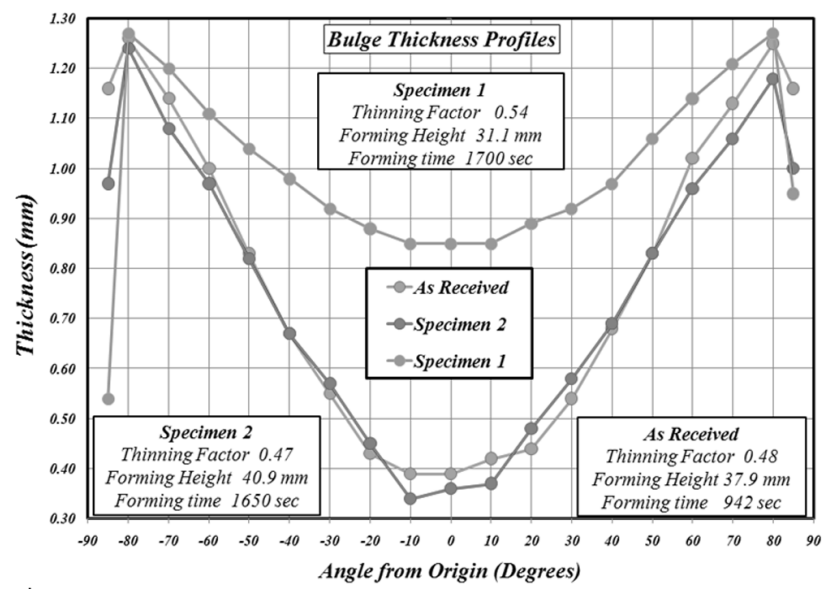

Figure 9. Thickness profiles for selectively heated AZ31 Mg bulgeformed samples.

Table 1. Summary of SPF results for the specimens shown in Figure 9

\begin{tabular}{llll}
\hline & As Received & Specimen 1 & Specimen 2 \\
\hline Forming Temperature $\left[{ }^{\circ} \mathrm{C}\right]$ & 400 & 400 & 400 \\
Selective Heating Temperature & - & $400 \& 450$ & 400 \\
{$\left[{ }^{\circ} \mathrm{C}\right]$} & & & \\
Selective Heating Time [min] & - & $15 \& 15$ & 25 \\
Thinning Factor & 0.48 & 0.54 & 0.47 \\
Forming Height [mm] & 37.9 & 31.1 & 40.9 \\
Forming Time [s] & 962 & 1700 & 1650 \\
Minimum Thickness [mm] & 0.36 & 0.85 & 0.34 \\
Failure & Yes & No & Yes \\
\hline
\end{tabular}

ference in the microstructure explains why the specimen failed to approach failure with a pressure profile for the as-received microstructure. The 1700 second forming without failure provides support to the previous results obtained from superplastic stretching tests of fully-annealed tensile specimens. As for specimen 2 , it did fail, but again the forming time was $\sim 1650$ seconds, which is substantially longer than expected if there were no microstructure effects from selectively heating. All the results are summarized in Table 1.

As for the thinning effects, it is hypothesized prior to forming that the effects would be negligible, since grain size gradients were so small. It was desired to achieve a gradient of at least $3 \mu \mathrm{m}$ before thinning effects could be examined, which was not possible due to the lack of proper cooling fixtures for the UV light experiments. Yet, if one looks at the forming heights, specimen 3 did provide a taller bulge which means that the material needed to stretch more. But this is most likely due to the slower strain rate during forming, which also provides a major influence on forming thickness, as shown by (Abu-Fahra 2007) for the optimization of superplastic forming [12].

For specimen 1, if one looks closely at the two edges of the plot in Figure 9, a major drop in thickness is noticed. With less grain growth at the top, the material flow stress is a bit lower at the top allowing for more deformation. This relates to the property changes seen in the pre annealed uniaxial tests above. Therefore, specimen 1 provides a very little but important result towards thinning influences and thus presenting reason to continue the research, especially since the achieved versus desired tempera- ture gradients are much different. A more desired temperature gradient profile would provide a maximum temperature of $200^{\circ} \mathrm{C}$ slightly inside the forming die edge, and at least a temperature of $350^{\circ} \mathrm{C}$ near the center. This should allow for substantial grain growth in the order of $5 \mu \mathrm{m}$ around the centre, versus minimal grain size growth near the edge, based on Figure 2.

\section{Summary}

Through a collective series of samples for different temperatures, annealing times and sheet metal thicknesses; a 3-dimensional contour plot for static grain was generated. The contour plot can be used for future pre-annealing research and selective grain growth studies, as it was shown for the selective heating work presented here. If future superplastic uniaxial setup can be operated without the preheating involved in this work, the grain growth curve can also be very useful in generating complete preannealed superplastic forming studies. For this work, the microstructure gradients in the tensile specimens were small, yet there were clear effects that can be used to provide thickness control in bulge-formed sheets. The alterations in the flow and ultimate stresses present in this work give a positive insight for microstructural engineering in SPF applications. The bulge-forming results provided minimal selective heating insight, though annealing effects did provide major alterations and a successful means of selectively-heating has been determined in the IR spot heater. With a simple heat exchanger, the desired temperature gradient for similar AZ31 magnesium specimens can be achieved in the deformation zone. With such information and the constant improvement in material modeling abilities, selective microstructural engineering has the ability to push lightweight alloys to more widespread applications, especially at this time, where it is essential to minimize energy consumption in the transportation sector.

\section{References}

[1] A. Chokshi, A. Mukherjee, T. Langdon, Materials Science and Engineering 1993, 10, 237.

[2] X. Ding, H. Zbib, C. Hamilton, A. Bayoumi, Journal of Materials Engineering and Performance 1995, 4, 474.

[3] K. A. Padmanabhan, G. J. Davis, Superplasticity, SpringerVerlag, Berlin 1980.

[4] M. Khraisheh, F. Abu-Farha, M. Nazzel, K. Weinmann, Combined Mechanics-Materials Based Optimization of Superplastic Forming of Magnesium AZ31 Alloy. Annuals of the CIRP, 2006, 55, 233-236.

[5] F. Abu-Farha, M. Khraisheh, On the Superplastic Deformation of AZ31 Magnesium Alloy. Proceedings of the $7^{\text {th }}$ International Conference on Magnesium Alloys and Their Applications, Dresden, Germany, 6-9 November 2006, 399-405.

[6] F. Abu-Farha, M. Khraisheh, Journal of Advanced Engineering Materials 2007, 9, 777.

[7] M. Khraisheh, F. Abu-Farha, K. Weinmann, Experimental Investigation of Post-Superplastic Forming Properties of AZ31 Magnesium Alloy. Annuals of the CIRP, 2007, 56, 289-292. 
[8] P. Bate, J. Jiang, Metallurgical and Materials Transaction A 1996, 27A, 3250.

[9] S. Rhaipu, Journal of Materials Processing Technology 1998, $80-81,90$.

[10] M. Nazzal, Advanced Finite Element Modeling and Stability Analysis of the Superplastic Forming Process. University of Kentucky, Dissertation, 2007.

[11] Metals Handbook, Properties and Selection: Nonferrous Alloys and Special-Purpose Materials, 10th ed., ASM International, 1990.
[12] F. Abu-Farha, Integrated Approach to the Superplastic Forming of Magnesium Alloys. University of Kentucky, Dissertation, 2007.

[13] A. Mukherjee, A. Dutta, Materials Science and Engineering A 1992, 157, 9 . 